\title{
AN OVERVIEW OF OIL BASED DRILL CUTTINGS WASTE ENVIRONMENTAL EFFECT AND DISPOSAL TREATMENTS
}

\author{
Osama Sharafaddin ${ }^{1}$, Ion Onuțu ${ }^{1}$ \\ Universitatea Petrol-Gaze din Ploieşti, bd. Bucureşti, 39, Ploieşti. Romania \\ e-mail; osharaf14@gmail.com;
}

DOI: 10.51865/JPGT.2021.01.04

\begin{abstract}
The drilling fluid is essential for drilling operations in the oil and gas industry. It is a complex mixture of organic and inorganic materials blended together to achieve desired multi-functions. There are several types of drilling fluid commonly in use, oil-based drilling fluid considered the most hazardous and harmful for the surrounding environment because of contaminated waste produced, normally consisting of diesel, oil, asphalt, polymers, crude oil and surfactants. Produced drill cuttings are contaminated by hydrocarbons, and other chemical additives. The produced drill cuttings are hazardous for environment as they contain polycyclic aromatic hydrocarbons and undesirable heavy metals. Presently, various oil and gas operator companies in Yemen and other parts of the world dispose the drilling wastes in excavated pits or landfill sites. It is not acceptable to deal with such hazardous substances in this manner. Other operator companies use thermal desorption technique as a separation method. This method still has many disadvantages. Therefore, it is vital to search for sufficient and efficient technologies and processes to treat oil-based drilling wastes as the existing methods in use cannot be considered as a viable solution to eliminate the environmental damaged caused by contaminated drill cuttings. This paper review three existing experimental methods of extraction that have significant total organic carbon removal efficiency and highlighted factors that effect on the extraction efficiency. They are; supercritical water oxidation, superheated steam extraction, and supercritical carbon dioxide extraction. The stated experimental studies have shown promising results and efficiency in extraction of carbon content and are considered environmentally friendly.
\end{abstract}

Keywords: Drill cuttings treatment, supercritical water oxidation, superheated steam extraction, supercritical carbon dioxide extraction

\section{INTRODUCTION}

Drilling fluids have high severe impact on environment. The degree effect is based on drilling fluid system, dosage, and chemical exposure time on living organism. The environmental impact can be determined by the physical and chemical properties of 
drilling fluid waste. There are several classifications of drilling fluid such as waterbased fluid, oil based fluid, synthetic based fluid, and pneumatic based fluid and drill in fluid. The design and selection of which drilling fluid type to use depends on various criteria such as subsurface pressure, well temperature, overall cost, well lithology, logistic challenges and impact on environment.

Oil based drilling fluid is considered the best drilling performance fluid and is widely still in use. Oil based drill cuttings contain high percentage of hydrocarbons, heavy metal, additive chemicals and salt. Previous studies confirmed the presence of certain metals such as $\mathrm{Cd}, \mathrm{Cr}, \mathrm{Ni}, \mathrm{Cu}, \mathrm{Zn}, \mathrm{Ba}, \mathrm{Fe}$ and others in drill cutting that have potential effect on environment [1,2]. The aromatic hydrocarbons and mineral oils were shown to be toxic to living organism on both offshore and onshore surrounding. As cuttings generated from drilling operation are coated with oil, they are considered soil contaminants and hazardous to health and environment through the reaction with surface water, ground water, and vegetation (Phyptotoxicity, bioaccumulation) that would cause severe ecophysiological impact [3].

The current oil based drilling fluid in use are: $\bullet$ Paraffins (alkanes) with a single bond carbon such as linear, branched (iso) or cyclic (Ring) with carbon chain link of C10 to $\mathrm{C} 20 \bullet$ Olefins (Alkenes) with double bond type that could be alpha olefins with double bond or internal olefins with carbon chain length of C15 to C18 [4].

Several international regulations and guidelines are implemented to control drill cutting disposal such as oil spill prevention, administration and response (OSPAR), United stated environmental protection agency (EPA), marine emergency mutual aid centre (MEMAC), Chinese national standard (GB4914-2008), American petroleum institute (API) and Barcelona convention (Table 1).

Table 1. Comparison of different oil-Based drill cuttings discharge policies [5]

\begin{tabular}{|l|l|}
\hline $\begin{array}{l}\text { The United States Environmental } \\
\text { Protection Agency (USEPA) }\end{array}$ & $\begin{array}{l}\text { Prohibits the release of oil-based drill } \\
\text { cuttings in all regions }\end{array}$ \\
\hline Norway & $\begin{array}{l}\text { Cuttings with less than 1\% oil can be } \\
\text { discharged, but there implements a zero } \\
\text { discharge policy in the Barents Sea }\end{array}$ \\
\hline Brazil & $\begin{array}{l}\text { Does not allow emissions of oil-based drill } \\
\text { cuttings and low-mineral oils, but it allows } \\
\text { to discharge the enhanced mineral oil- } \\
\text { based muds approved by IBAMA (the } \\
\text { Brazilian Institute of Environment and } \\
\text { Renewable Natural Resources) }\end{array}$ \\
\hline $\begin{array}{l}\text { North Sea's (implement OSPAR } \\
\text { Convention Oslo and Paris Commissions) }\end{array}$ & $\begin{array}{l}\text { Specifies that oil-based drill cuttings not } \\
\text { only need to contain less than 1\% oil, but } \\
\text { also pass toxicity tests to determine } \\
\text { whether they are hazardous substance }\end{array}$ \\
\hline
\end{tabular}


Therefore, the main objective in this paper is to review three different methods used for disposal treatments of oil based fluid cuttings and waste. The three methods separate the drilling fluids from cuttings in order to achieve the required specifications for disposal and keep the environment clean. These methods are supercritical water oxidation, superheated steam extraction, and supercritical carbon dioxide extraction. Further, the methodology of each method and the equipment are reviewed.

\section{RESEARCH METHODOLOGY}

Treatment of oil based drill cutting is becoming a concern for many oil producer countries. There variety of treatment methods for disposal of drill cuttings. Disposal technologies are categorized into three main types. First category is containment method like Cuttings re-injection (CRI) which it applicable and common technique for disposal of cuttings by grinding and then inject them to subsurface formation [6], landfills or burial methods [2]. Second category is called the decomposition method such as bioremediation and phytodegradation that degrades harmful and toxic compounds in drill cuttings [7].

The third category of treatment is contaminant separation from the drill cutting such as thermal desorption treatment which it the most commercially in use until today, that adapted electromagnetic induction heating during continuous transfer of the cuttings to fixation unit and operating in different temperatures. Samples are treated to reduce the total petroleum hydrocarbon content [8]. The second treatment is washing of contaminated soil and cuttings using surfactants that have a mixed and long molecules consisting of hydrophilic and hydrophobic moieties to remove total petroleum hydrocarbon at ambient temperature [9]. The third treatment is microwave heating and drying that uses an oven with microwave emitting sources for drying drill cuttings to remove hydrocarbon content.

As mentioned above the most used separation method in the oil and gas industry is the thermal desorption treatment. It has many disadvantages such as system requires a large heating area that makes the system bulky, it consumes a lot of heat, air emissions from thermal desorption operations, and pollutant residues $[10,5]$. Thus, it is essential to study and evaluate other innovative separation methods such as supercritical water oxidation, superheated steam extraction, and supercritical carbon dioxide extraction. Experimental base studies have shown efficiency in hydrocarbon extraction and the same time are considered environmentally friendly process that can be applicable on the oil and gas field.

\subsection{Supercritical water oxidation method}

Removing of oil from cuttings using supercritical water oxidation has shown significant results. This method had been investigated in a batch reactor under various oxidation coefficients (OC, 1.5-3.5), temperature up to $500{ }^{\circ} \mathrm{C}$ and reaction time up to 10 minutes. Theis step of the preheating separates the targeted sample to oil, gaseous, aqueous, and solid phase. The removal efficiency of total organic carbon (TOC) could reach up to 98 $\%[11,12]$. 
As shown in table 2 carbon extraction increased with increase of temperature, reaction time, and oxidation coefficient. The maximum carbon recovery was obtained when temperature reached $500{ }^{\circ} \mathrm{C}$. Likewise, Oxidation Coefficient (OC) has great impact on extraction when increased to 3.5. Even the time reaction showed tremendous influence to get carbon extraction from $71.68 \%$ to $99.53 \%$ at 10 minutes [11].

Table 2. Supercritical water oxidation experimental conditions for organic pollutants [11]

\begin{tabular}{|c|c|c|c|c|c|}
\hline $\begin{array}{c}\text { Temperature } \\
(\mathrm{K})\end{array}$ & $\begin{array}{c}\text { Oxidation } \\
\text { coefficient } \\
\text { OC }\end{array}$ & $\begin{array}{c}\text { Reaction } \\
\text { time } \\
\mathrm{t} \text { min }\end{array}$ & $\begin{array}{c}\text { Liquid } \\
\text { products } \\
\text { total organic } \\
\text { content } \\
\mathrm{mg} / \mathrm{l}\end{array}$ & $\begin{array}{c}\text { Solid product } \\
\text { residual total } \\
\text { organic content } \\
\mathrm{mg} / \mathrm{g}\end{array}$ & $\begin{array}{c}\text { Carbon } \\
\text { recovery } \\
\%\end{array}$ \\
\hline 400 & 2.5 & 3 & 84.53 & 28.96 & 79.91 \\
\hline 450 & 2.5 & 3 & 73.75 & 25.97 & 94.12 \\
\hline 500 & 2.5 & 3 & 58.2 & 19.06 & 98.70 \\
\hline 475 & 1.5 & 3 & 46.09 & 42.74 & 83.76 \\
\hline 475 & 2.5 & 3 & 63.39 & 17.82 & 98.70 \\
\hline 475 & 3.5 & 3 & 50.89 & 16.33 & 99.02 \\
\hline 475 & 2.5 & 1 & 59.78 & 38.19 & 71.68 \\
\hline 475 & 2.5 & 5 & 41.00 & 16.70 & 99.38 \\
\hline 475 & 2.5 & 10 & 26.81 & 14.14 & 99.53 \\
\hline
\end{tabular}

Furthermore, X-ray diffractometry (XRD) and scanning electron microscopy (SEM) results proved that supercritical water oxidation could efficiently remove organic pollutants from drill cuttings and clearly does not have any impact on microstructure and composition of the inorganic component [13]. This provides new harmless and environmental approach for disposal of oil based drill cuttings [11]. The technical problem of this technology is corrosion, plugging, salt deposition, presence of suspended solids, and high implementation cost [12].

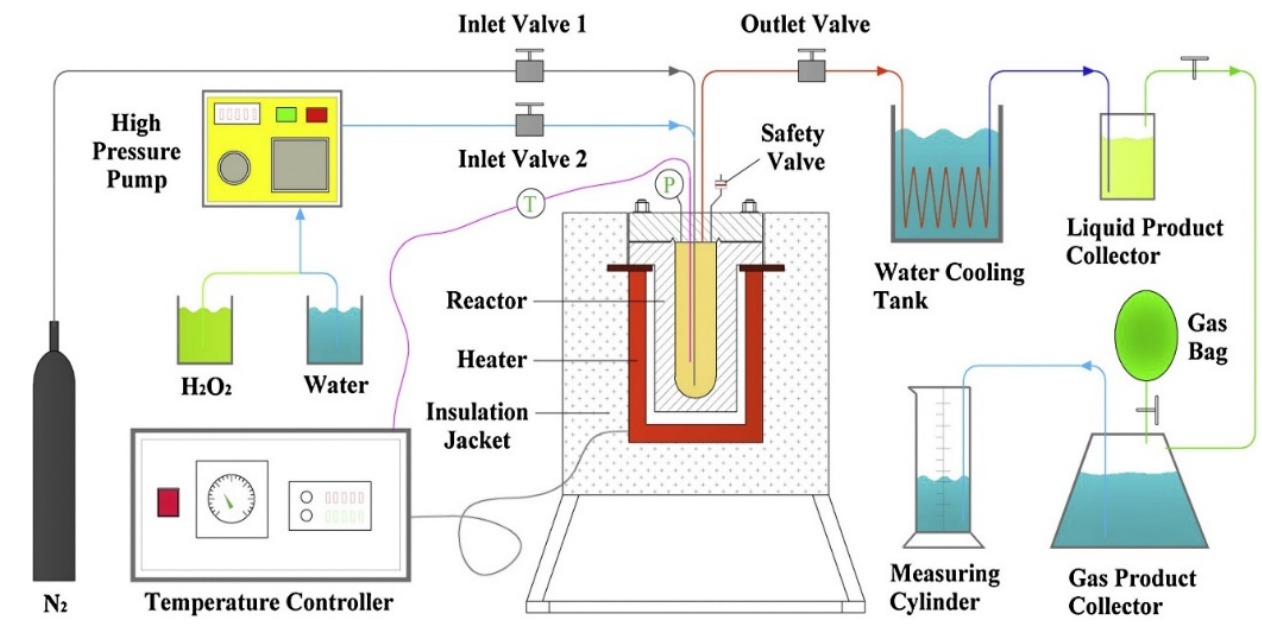

Figure 1. Supercritical water oxidation of oil based cuttings experimental diagram [11] 


\subsection{Superheated steam extraction method}

Superheated steam extraction is considered an applicable removal treatment. After this treatment the oil based drill cuttings become not hazardous any more as oil content is reduced significantly. This method environmentally is friendly since it is mainly using flowing water under high temperature and pressure. Figure 2 illustrates the extraction vessel. As samples are loaded in the sample boat, the heater turn on to warm up the extraction vessel to different temperatures $\left(175-225{ }^{\circ} \mathrm{C}\right)$. High-pressure pump is used to flow water in different rates $(2-8 \mathrm{ml} /$ minute) with various pressures between $0.6-5.5$ $\mathrm{MPa}$. Liquid water accumulated at the bottom of vessel and the cuttings are dumped after cooling [14].

The effect of temperature was analysed at $175,200,225,250$ and $275{ }^{\circ} \mathrm{C}$ under constant water flow rate $6 \mathrm{ml} / \mathrm{min}$. It showed that the TOC of the studied sample at $175^{\circ} \mathrm{C}$ was $73 \mathrm{mg}$ g-1 and decreased gradually to $59 \mathrm{mg}$ g-1 with increase of temperature. The study concluded that there are other parameters beside temperature that have effect on the efficiency of the extraction such as pressure, drill cuttings characteristics, and stream flow rate [14].

$\mathrm{X}$-ray diffraction and scanning electron microscopy examination indicated that there was no significant microcrystalline structure changes in drill cuttings during treatment and ascertain the effectiveness of contaminations extraction. It is a green process as it uses water during the treatment [14]. The drawback of this method is the high energy consumption compared to other methods due to the required high temperature. Capital cost, as it requires large quantity of continuous operated steam to be fed in the system. Experimental apparatus needs to be properly installed and sealed to prevent any potential leaks. And after the treatment accumulated liquid needs to be analysed and treated from any TOC residual prior discharge $[14,15]$.

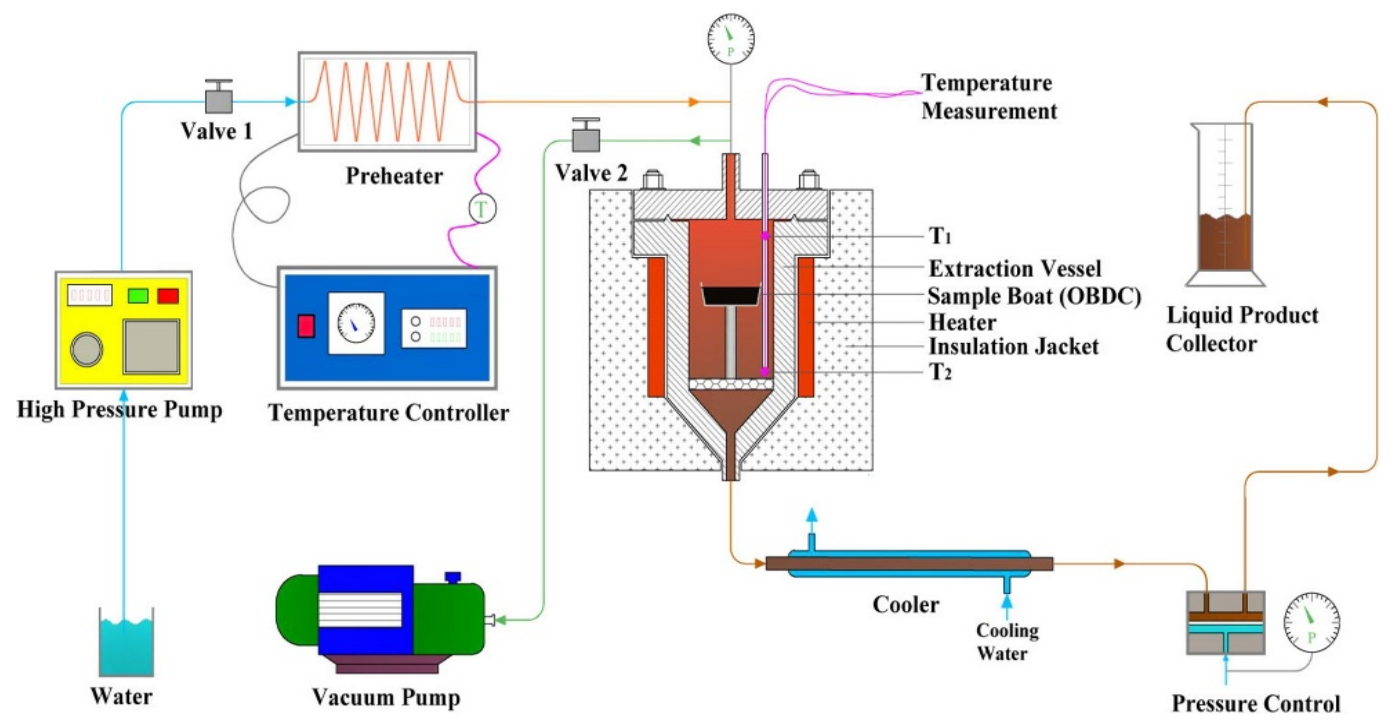

Figure 2. Superheated steam extraction experimental diagram [14]. 


\subsection{Supercritical carbon dioxide extraction method}

$\mathrm{CO}_{2}$ in supercritical conditions has been broadly used in various industrial extraction processes, such as fragrances, coffee bean decaffeination, and flavours selection or pharmaceutical molecules production. $\mathrm{CO}_{2}$ achieves supercritical state when its temperature above $304 \mathrm{~K}$ and pressure higher than $7.38 \mathrm{MPa}$. Firstly, measure the oil content on the sample by using ultraviolet spectrophotometer after that as shown in figure 3 to load the oil based waste into extraction vessel. Charge $\mathrm{CO}_{2}$ into vessel using booster pump at $18 \mathrm{MPa}$ pressure and $318 \mathrm{~K}$ temperature. Exposure time scale from 10 min to $240 \mathrm{~min}$. The extracted oil is discharged slowly toward the separator to separate the $\mathrm{CO}_{2}$. The flow gas meter measures the flow rate of the $\mathrm{CO}_{2}$. $[16,17]$.

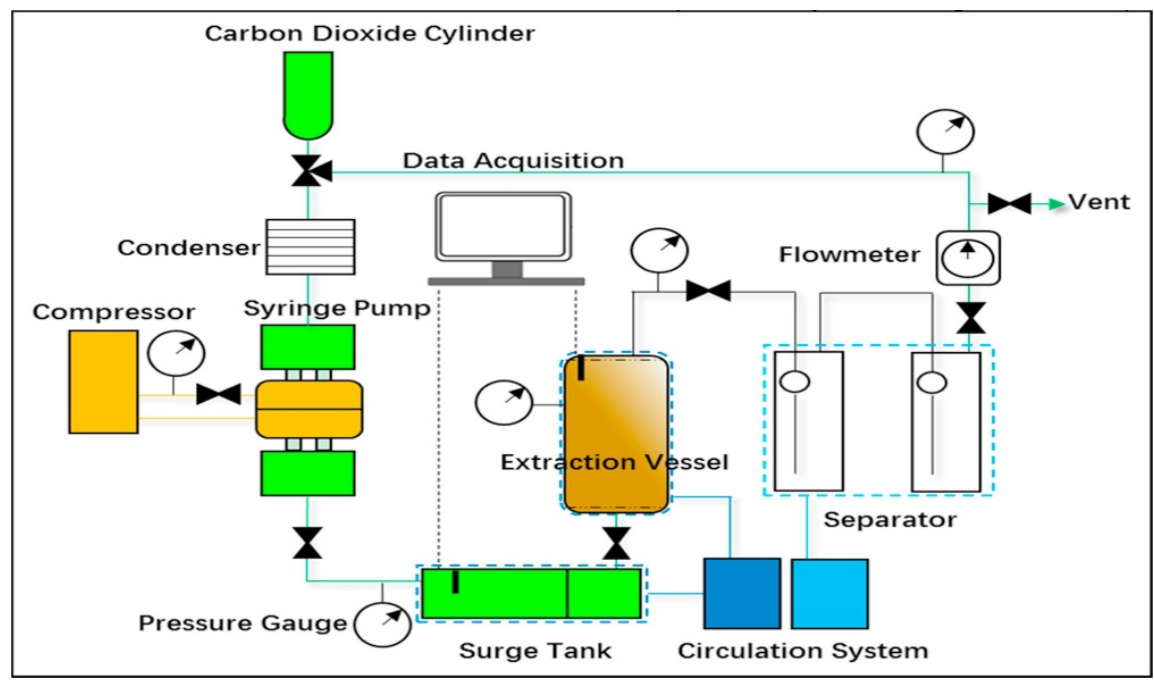

Figure 3. Supercritical carbon dioxide extraction experimental diagram [16]

Figure 4 shows another previous study, that when temperature increased from $313 \mathrm{~K}$ to $333 \mathrm{~K}$, resulting an increase of the amount of removed contaminant from $0.18 \mathrm{~g} / \mathrm{L}$ to $0.22 \mathrm{~g} / \mathrm{L}$ [18]. The study concluded that the efficiency extraction depends on suitable parameters of temperature, pressure, time, and mass of supercritical carbon dioxide. This process has strong ability to extract light components and n-alkanes hydrocarbon structure in drill cuttings and the collected hydrocarbons can be reused in drilling operation.

X-ray diffraction and scanning electron microscopy examination confirmed that there was no significant crystalline structure modification and effective contaminations extraction [18]. Thus, it is considered operative process, environmentally friendly, reliable and has good performance to extract contaminants from oil based drill cutting. The main advantages that it is not toxic, safe, odourless, non-flammable, readily available, easily to achieve critical point, leaves no harm residues, strong penetrating power, inexpensive, and has great separation capability [19,5]. Moreover, the recovered hydrocarbons properties are unchanged by the extraction, further they may be recovered and potentially reused $[16,18]$. 


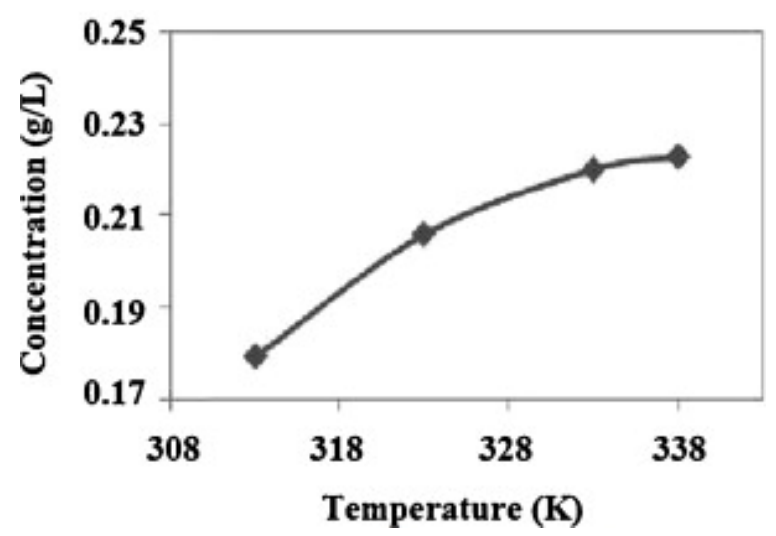

Figure 4. Effect of temperature on the removal of drilling waste contaminants [18].

Figure 5 shows the oil-based cuttings before supercritical carbon dioxide extraction and after the extraction. It is obvious that this process has a remarkable hydrocarbon extraction efficiency on drill cutting.

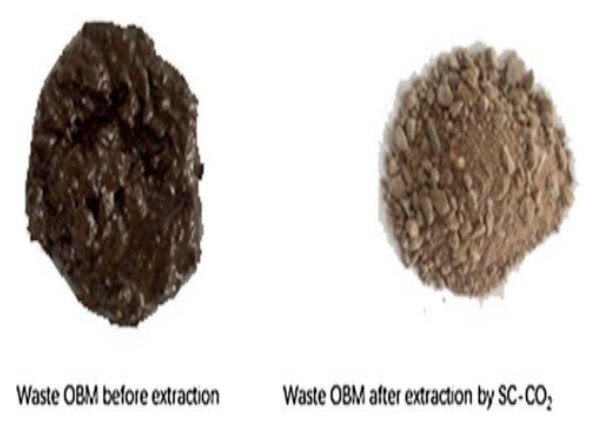

Figure 5. Oil based waste before and after

Supercritical carbon dioxide extraction [16]

\section{CONCLUSION}

- Conclusions for the three treatment methods; supercritical carbon dioxide extraction, superheated steam extraction and supercritical water oxidation are summarized below:

Temperature, exposure time and pressure have major influence and are the main contributors to extraction efficiency.

$\checkmark$ Drill cutting characteristics play important role in removal efficiency.

$\checkmark$ X-ray diffraction and scanning electron microscopy examination were conducted for the three methods and the results confirmed that there were no significant crystalline structure modification and the efficiency of contaminations extraction.

$\checkmark$ After treatment of oil-based drilling cuttings, oil contents noticeably diminished which resulted in a reduction of hazardous impact on environment and can be considered as non hazardous wastes. These methods not only extract hydrocarbon content but also other hazardous components. 
$\checkmark$ Based on the review that the supercritical carbon dioxide extraction is the most efficient separation technique than the other methods in extraction of total organic carbon. As it has special properties such as high diffusivity, high density and low viscosity that enable this scheme to have tremendous removal efficiency.

$\checkmark$ The factors that need to be taken into consideration prior designing and implementation of any extraction method are expertise, environmental standards, availability of required materials, country regulations, operational cost, duration of treatment, space availability, economic consideration, logistics, health and safety.

$\checkmark$ Results obtained from laboratory scale experiments have promising TOC extraction efficiency. Further investigation is required to ascertain if the results are scalable to an industrial level process.

\section{REFERENCES}

[1] Pozebon D., Heavy metals contribution of non-aqueous fluids used in offshore oil drilling, 84(1), pp. 53-61, 2005.

[2] Bakke T., et al., Environmental impacts of produced water and drilling waste discharges from the Norwegian offshore petroleum industry, 92, pp. 154-169, 2013.

[3] Siddique S., et al., Oil based drilling fluid waste, an overview on environmentally persistent pollutants, IOP Conference Series, Materials Science and Engineering, 2017.

[4] Caenn R., Darley H.C., and Gray G.R., Composition and properties of drilling and completion fluids, Gulf professional publishing, 2011.

[5] Huang Z., Xu Z., Quan Y., Jia H., Li J., Li Q., Pu K., A review of treatment methods for oil-based drill cuttings. Paper presented at the IOP Conference Series: Earth and Environmental Science, IOP Publishing, 2018.

[6] Shokanov T., et al., Systems and methods for real-time controlling of cuttings reinjection operations, Google Patents, 2018.

[7] Rezaei M., Shavandi M., Dastgheib S., Amoozegar M, Bioremediation of oil-based drill cuttings by a halophilic consortium isolated from oil-contaminated saline soil. 3 Biotech 8, pp. 229, 2018.

[8] Zhang X., et al., Pilot experiment of oily cuttings thermal desorption and heating characteristics study, 9 (2): pp. 1263-1270, 2019.

[9] Nwinee S.A., Sustainable treatment of oil contaminated waste: oil-based mud (OBM) drill cuttings and soil, Robert Gordon University, 2018.

[10] Mkpaoro M.I.F., Okpokwasili G.C., Joel O.F., A Review of Drill-Cuttings Treatment and Disposal Methods in Nigeria-The Gaps and Way Forward. In SPE Nigeria Annual International Conference and Exhibition. Society of Petroleum Engineers, 2015. 
[11] Chen Z., Chen Z., Yin F., Wang G., Chen H., He C., Xu Y., Supercritical water oxidation of oil-based drill cuttings, Journal of hazardous materials, 332, pp.205-213, 2017.

[12] Bermejo M.D., Cocero M.J., Supercritical water oxidation: a technical review. AIChE Journal, 52(11), pp. 3933-3951, 2006.

[13] Chen Z., Zheng Z., Li D., Chen H., Xu Y., Continuous supercritical water oxidation treatment of oil-based drill cuttings using municipal sewage sludge as diluent, Journal of hazardous materials, 384, pp.121225, 2020.

[14] Chen Z., Zhou J., Chen Z., Chen H., Chen Q., He C., Liu X., Yuanjian X., A laboratory evaluation of superheated steam extraction process for decontamination of oil-based drill cuttings, Journal of environmental chemical engineering, 6(5), pp.66916699, 2018.

[15] Mujumdar A.S., Principles, classification and selection of dryers. Handbook of industrial drying, 2006, 3 pp.3-32;

[16] Ma B., et al., Experimental study on harmless disposal of waste oil based mud using supercritical carbon dioxide extraction, 252, pp. 722-729, 2019.

[17] Jones C. R., Treatment of oily drill cuttings slurries using supercritical carbon dioxide, 2010.

[18] Khanpour R., Sheikhi-Kouhsar M.R, Esmaeilzadeh F., and Mowla D., Removal of contaminants from polluted drilling mud using supercritical carbon dioxide extraction, The Journal of Supercritical Fluids, 88, pp.1-7, 2014.

[19] Street C.G., Guigard S.E., Treatment of oil-based drilling waste using supercritical carbon dioxide, Journal of Canadian Petroleum Technology, 48(06), pp.26-29, 2009. 